\title{
PREVALENCE OF MOLECULAR SUBTYPES OF CARCINOMA OF BREAST- A STUDY FROM NORTH INDIA
}

\author{
Surinder Kumar Atri' ${ }^{1}$ Virender Mohan Rana², Minakeshi Rana ${ }^{3}$, Zahoor Ahmed ${ }^{4}$
}

${ }^{1}$ Associate Professor, Department of Pathology, Government Medical College, Jammu, Jammu and Kashmir. ${ }^{2}$ Demonstrator, Department of Pathology, Government Medical College, Jammu, Jammu and Kashmir. ${ }^{3}$ Consultant Gynaecology and Obstetrics, District Hospital Samba, Jammu, Jammu and Kashmir Health Services, Jammu \& Kashmir. ${ }^{4}$ Associate Professor, Department of Surgery, Government Medical College, Jammu, Jammu and Kashmir.

\section{BACKGROUND}

ABSTRACT

Carcinoma breast is a heterogenous disorder with varying clinical course and survival rates in same grade and stage of patients. Therefore, there is a need of classification system of carcinoma breast wherein the patients with similar clinical course and survival rates can be clubbed together in a subgroup. Molecular classification divides carcinoma into four categories based on ER/PR/HER2/neu expression: ER+ and/or PR+ and HER-2/neu- (Luminal A), ER+ and/or PR+ and HER-2/neu+ (Luminal B), ER- and/or PRand HER-2/neu+ (HER-2/neu overexpressing), ER-, PR- and HER-2/neu- (Triple negative/Basal like). This classification has prognostic and predictive value and allows personalised, molecular targeted therapy. There is a geographical difference in the prevalence of these molecular subtypes, similar to the incidence of carcinoma breast.

The aim of our study is to classify and define precisely the prevalence of molecular subtypes of carcinoma breast in our population using ER, PR and HER-2/neu immunohistochemistry on formalin-fixed paraffin-embedded blocks and to correlate these subtypes with histological and clinical features. The objective of our study is to evaluate the prevalence of molecular subtypes of carcinoma breast in our Population.

\section{MATERIALS AND METHODS}

It was an observational study wherein all cases of carcinoma breast from January 2010 to Dec. 2016 were retrieved, reviewed, graded and staged according to the 2003 WHO histological classification of breast tumours. Immunohistochemistry was for oestrogen receptor (ER), progesterone receptor (PR) and HER-2/neu was done in those cases where there was clinical requisition. Statistical analysis and correlation among categorical variables in the univariate analysis were determined using the Pearson-ChiSquare test. Significance was assumed at $\mathrm{p}$-value less than 0.05.

\section{RESULTS}

Of total 40 cases, ER was positive in 22, PR in in 18 and HER-2 in 12. Molecular subtypes were: Luminal A: 35\% (14/40), Luminal B: 22.5 (9/40), HER-2/neu group: $30 \%(12 / 40)$ and Triple negative group: $12.5(5 / 40)$.

\section{CONCLUSION}

The carcinoma breast is a heterogenous disorder clinically, morphologically and molecularly. Increasing number of molecular subtypes are being described which have prognostic and predictive value. Thus, emerging evidence shows promise that traditional classification of carcinoma breast can be supplemented with molecular classification for specialised, personalised and molecular targeted therapy.

\section{KEYWORDS}

Carcinoma Breast, Molecular Classification, Immunohistochemistry, Oestrogen Receptor, Progesterone Receptor, HER-2/neu.

HOW TO CITE THIS ARTICLE: Atri SK, Rana VM, Rana M, et al. Prevalence of molecular subtypes of carcinoma of breast- A study from North India. J. Evolution Med. Dent. Sci. 2017;6(89):6204-6207, DOI: 10.14260/jemds/2017/1349

\section{BACKGROUND \\ Carcinoma breast is the most common malignant neoplasm in females and second most common malignant neoplasm worldwide. $^{1}$ The incidence of carcinoma breast is progressively increasing over last decades ${ }^{2,3}$ and especially in India where carcinoma breast is now most common malignant neoplasm}

'Financial or Other Competing Interest': None.

Submission 07-10-2017, Peer Review 31-10-2017,

Acceptance 03-11-2017, Published 13-11-2017.

Corresponding Author:

Dr. Surinder Kumar Atri,

Associate Professor,

House No. 24, Lane 51, Behind Sunny Farms,

Greater Kailash Post Office, Gangyal, Jammu-180010,

Jammu and Kashmir.

E-mail: surinderkumaratri@gmail.com

DOI: $10.14260 /$ jemds/2017/1349

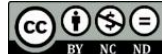

in women replacing carcinoma cervix. ${ }^{4}$ Mortality wise also carcinoma breast is one of the leading cause of cancer-related death in women worldwide. 5 Traditional classification of carcinoma breast is based on clinicopathological features like tumour size, histological type of carcinoma, histological grade and lymph node metastases. The patients are treated on the basis of tumour size, local invasion, lymph node metastases or distant metastases as defined by the American Joint Committee on cancer's TNM staging and classification. ${ }^{6}$ Treatment of carcinoma breast is multimodal. Prognosis and survival rates of the patients matched best with tumour size and presence of axillary lymph node metastases, but patients in the same group and stage can have markedly different clinical course and survival rates. ${ }^{7,8}$ Therefore, there is a need for classification of carcinoma breast where the subtypes can correlate with clinical course and survival rates. Although traditional classification still remains the main cornerstone 
for the diagnosis of these patients, molecular classification of carcinoma breast is used to identify subsets with significant prognostic and therapeutic implications. Perou et $\mathrm{al}^{9}$ for the first-time classified carcinoma breast into molecular subtypes based on their gene expression profiles as Oestrogen receptor $(E R)^{+} /$luminal-like, receptor tyrosine-protein kinase erbB-2 (Erb-B2), basal-like and normal breast tissue. Due to high cost of array analysis in clinical practice, classification protocols have incorporated immunohistochemistry in clinical practice. $10 \mathrm{~A}$ number of biomarkers are now used like ER, PR, HER-2/neu, MIB1/Ki-67, Cytokeratin (CK) 6/7, etc. All these markers have been successfully correlated to prognosis of patients with carcinoma breast.11-19 Therefore, we planned this study to classify of carcinoma breast by immunohistochemistry using ER, PR and HER-2 biomarkers in our local patients.

\section{MATERIALS AND METHODS}

It was an observational study. All cases of carcinoma breast signed out in the Department of Pathology from January 2010 to Dec. 2016 were retrieved from surgical pathology files and consult files of Govt. Medical College, Jammu. In total, 158 cases were identified over a period of seven years. Haematoxylin and eosin stained sections of all cases of carcinoma breast were re-examined and tumours were graded and staged according to the 2003 WHO histological classification of breast tumours. The morphological characteristics noted in all cases are tumour size, tumour grade and lymph node status.

\section{Immunohistochemistry}

Immunohistochemistry for oestrogen receptor (ER), progesterone receptor (PR) and HER-2/neu was done in only in 40 cases, in those cases where there was clinical requisition. Immunohistochemistry was done using streptavidin biotin conjugate (LSAB) immunoperoxidase technique on formalin-fixed, paraffin-embedded one representative cross-sectional slide per tumour, displaying a maximum of tumour mass. The monoclonal antibodies were obtained from M/s Novocastra Laboratories, Newcastle upon Tyne, UK. The LSAB kit was obtained from M/s Dako Patts, Denmark. Negative control was obtained by omitting primary antibody. These stains were interpreted as per the literature.

Statistical analysis and correlation among categorical variables in the univariate analysis were determined using the Pearson Chi- Square test. Significance was assumed at $\mathrm{p}$ value less than 0.05 .

\section{RESULTS}

\section{Clinicopathological Parameters}

Mean age of patients included in the study was 52 years ranging from 34-76 years. The common clinical presentation was breast lump [83.54\% (132/158)], Nipple discharge [28.4 $\%$ (18/158)] and axillary lymph adenopathy [5.06\% (8/158)]. The most frequent histological type of carcinoma breast was infiltrating ductal carcinoma (91.13\%). There were five cases of lobular carcinoma, breast, three cases of papillary carcinoma breast, 2 cases of mucinous carcinoma breast, three cases of medullary carcinoma breast and one case of metaplastic carcinoma.

\section{Tumour Size}

The average tumour size was $4.2 \mathrm{~cm}$ ranging from $1.2 \mathrm{~cm}$ to $8.5 \mathrm{~cm} .17 .7 \%(28 / 158)$ tumours were less than $2 \mathrm{~cm}$ (T1), $52.5 \%$ (83/158) were between $2-3 \mathrm{~cm}$ (T2) and 29.7\% (47/158) were greater than $5 \mathrm{~cm}$ (T3). Nine of 14 cases $(64.2 \%)$ of luminal A, Five of nine cases $(55.5 \%)$ of luminal B, 10 of 12 cases of HER-2 positive group and all cases (5/5) of triple negative group were $>2 \mathrm{~cm}$.

\section{Tumour Grade}

Of the total 158 total cases, 98 (62\%) were of Nottingham modification of Bloom-Richardson grade II, 14 (8\%) were grade III and 46 (29\%) were grade I. All histological grade III tumours were of triple negative group. None of the cases in triple negative group were of grade II or I. Molecular subtypes of carcinoma breast divided on the basis of immunohistochemistry for ER, PR and HER-2/neu expression are different from histological grades $(\mathrm{P}=0.001)$.

\section{Lymph Nodes}

$38(24 \%)$ of 158 cases showed lymph node metastasis. Four (80\%) of 5 cases of triple negative subtype showed lymph node metastases. Five (35\%) cases of luminal A, Three (33 \%) cases of luminal B and 2 cases of HER-2/neu group had lymph node metastasis.

\section{Oestrogen Receptor Status}

Oestrogen receptor (ER) expression was positive in 22 (55\%) of 40 cases (Fig. 1), of these 22 tumours 15 (68.18\%) were histologically grade II, Five $(22.7 \%)$ were grade III and 2 (9.09\%) were grade I. The correlation between grade and ER status was statistically significant.

\section{Progesterone receptor Status}

Progesterone receptor (PR) expression was seen in 18 (45\%) of 40 cases (Fig. 2), of these 18 cases, 12 (66.6\%) were of grade II, 4 (22.2\%) were grade III and two (11.1\%) were grade I. The correlation between grade and PR status was statistically significant.

\section{HER-2/neu}

12 (30\%) of the 40 cases in which immunohistochemistry for HER-2/neu was done, were positive for HER-2/neu (Fig 3). Of these twelve cases, eight of were of histological grade II and 2 each of grade III and I.

\section{Molecular Classification Based on ER, PR and HER-2/neu Expression}

Based on the Immunohistochemistry for ER, PR and HER - 2. The cases were divided into four Molecular Groups-

a) Luminal A: $35 \%(14 / 40)$.

b) Luminal B: $22.5(9 / 40)$.

c) HER-2/neu group: $30 \%(12 / 40)$.

d) Triple negative group: $12.5(5 / 40)$. 


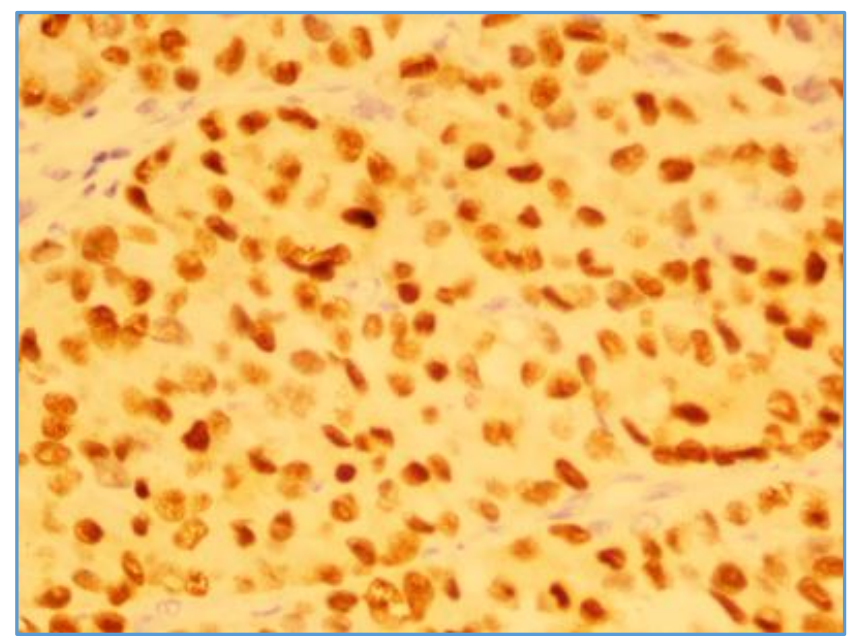

Figure 1. Immunohistochemistry for Oestrogen Receptor (ER) Showing Strong Nuclear Positivity [400X]

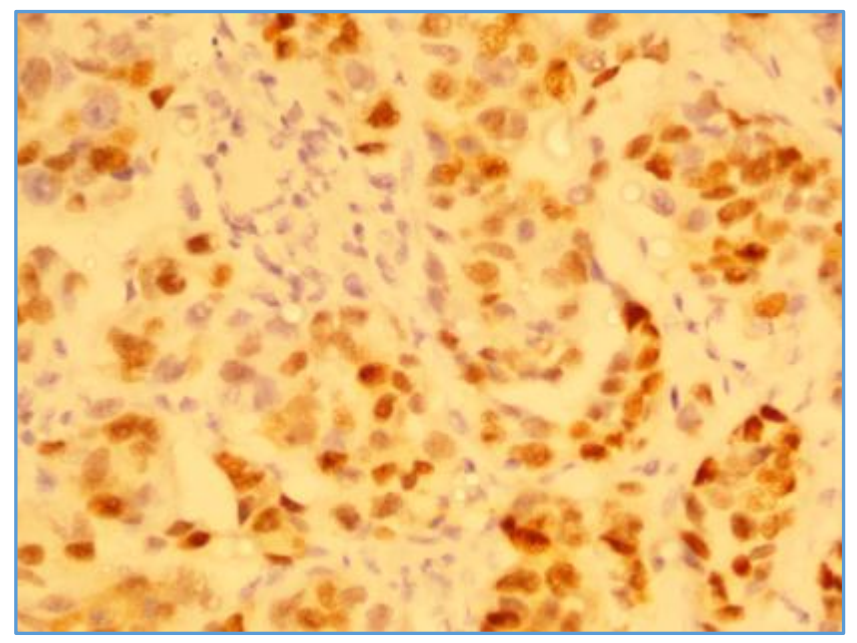

Figure 2. Immunohistochemistry for Progesterone Receptor (PR) Showing Strong Nuclear Positivity [400X]

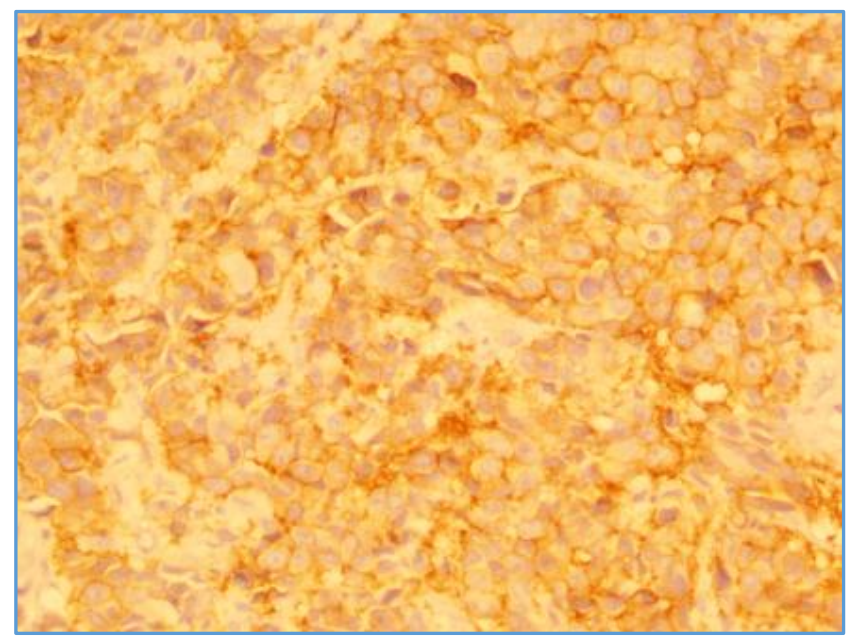

Figure 3. Immunohistochemistry for HER-2 Showing Strong Cell Membrane Positivity [400X]

\section{DISCUSSION}

Carcinoma breast is the most common malignant tumour in females and its incidence is progressively increasing in women in India in spite of better health care system and improved economic conditions. Perhaps, increase in incidence is because of change in lifestyle of women in India. Women with carcinoma breast continue to die worldwide and many women with carcinoma breast have multiple relapses. Women with similar histological type and stage of tumour (TNM) have different clinical course and survival rates. This promoted for the molecular classification of carcinoma breast so that we can have specialised, personalised and targeted therapy.

In our study, the most common molecular subtype of carcinoma breast was luminal A (35 \%) expressing ER/PR and HER-2/neu negative. On comparison with similar study in our population, it is similar in being most common though the prevalence is low. In a study by Verma et al,20 PGI Chandigarh, the most common type was luminal A but prevalence was $47 \%$. The $2^{\text {nd }}$ most common molecular subtype was HER-2/neu group and in the study by Verma et al also this was second most common molecular subtype though again the prevalence is different. In their study, it was $21 \%$ and in our study, it is $30 \%$. Luminal B subtypes [ER/PR and HER -2] was 3rd (22\%) most common subgroup similar to the study at PGI Chandigarh. Least common type is triple negative group which was $12.5 \%$ in our study and $17 \%$ in study by Verma et al. We could not categorise basal cell subtype which is a subtype of triple negative group as we did not apply basal cell markers CK6/7 and EGFR. This could be the reason for differences in our study and the study by Verma et al. Though the number of cases in our study are limited but gives rough picture of prevalence of different molecular subtypes in our population. This will help our patients to have endocrine therapy and targeted therapy. Oestrogen was expressed in 55\% of tumours in our study which is slightly lower than reported in the literature (60$70 \%$ ). HER-2/neu positivity in our study was $30 \%$ which is comparable with the rate reported in the literature.

Updated guidelines ${ }^{21}$ from the European Group on Tumour markers (EGTM) since Feb. 2017 is that for selecting patients on endocrine therapy, both oestrogen receptors (ERs) and progesterone receptors (PRs) should be measured on all newly diagnosed invasive breast cancers. On the other hand, for selecting likely response to all forms of anti-HER-2 therapy (trastuzumab, pertuzumab, lapatinib or adotrastuzumab emtansine), determination of HER-2 expression or gene copy number is mandatory. Where feasible, measurement of ER, PR and HER-2 should be performed on recurrent lesions and the primary invasive tumour. Ki67 may be used for determining prognosis, especially if values are low or high. Although there are methodological problems in the determination of Ki67, but because of its clearly established clinical value, wide availability and low costs relative to the available multianalyte signatures, Ki67 may be used for determining prognosis.

\section{CONCLUSION}

The molecular genetic heterogeneity and the large number of genes involved in carcinoma breast can be gauzed from the morphological subtypes of carcinoma breast. These genes control cellular proliferation, differentiation and apoptosis. This clearly states that we have to study this genetic molecular heterogeneity in a variety of phenotypically different carcinoma breast. The carcinoma breast is a heterogenous disorder clinically, morphologically and molecularly. Increasing number of molecular subtypes are 
being described which have prognostic and predictive value. $9,22,23$ Thus, emerging evidence shows promise that traditional classification of carcinoma breast can be supplemented with molecular classification for specialised, personalised and molecular targeted therapy.

\section{REFERENCES}

[1] Jemal A, Bray F, Center MM, et al. Global cancer statistics. CA Cancer J Clin 2011;61(2):69-90.

[2] Hortobagyi GN, de la Salazar GJ, Pritchard K, et al. The global breast cancer burden: variations in epidemiology and survival. Clin Breast Cancer 2005;6(5):391-401.

[3] Anderson BO, Jakesz R. Breast cancer issues in developing countries: an overview of the breast health global initiative. World J Surg 2008;32(12):2578-85.

[4] Green M, Raina V. Epidemiology, screening and diagnosis of breast cancer in the Asia-Pacific region: current perspectives and important considerations. Asia Pac J Clin Oncol 2008;4:5-13.

[5] Paik S, Kim C, Wolmark N. HER-2 status and benefit from adjuvant trastuzumab in breast cancer. N Engl J Med 2008;358(13):1409-11.

[6] Edge SB, Byrd DR, Compton CC, et al. AJCC cancer staging manual. $7^{\text {th }}$ edn. New York, NY: Springer 2009:347-76.

[7] National Cancer Institute. Surveillance, Epidemiology, and End Results (SEER) program. http://www.seer.cancer.gov/ 2013.

[8] Van 't Veer LJ, Dai H, van de Vijver MJ, et al. Gene expression profiling predicts clinical outcome of breast cancer. Nature 2002;415(6871):530-6.

[9] Perou CM, Sørlie T, Eisen MB, et al. Molecular portraits of human breast tumours. Nature 2000;406(6797):747-52.

[10] Goldhirsch A, Wood WC, Coates AS, et al. Panel members: Strategies for subtypes-dealing with the diversity of breast cancer: highlights of the St. Gallen International Expert Consensus on The Primary Therapy of Early Breast Cancer 2011. Ann Oncol 2011;22(8):1736-47.

[11] Tavassoli FA. Pathology of the Breast. 2nd edn. Stamford, Connecticut: Appleton \& Lange 1999.
[12] Moinfar F. Essentials of diagnostic breast pathology. Springer, Berlin Heidelberg 2007.

[13] Soerjomataram I, Louwman MW, Ribot JG, et al. An overview of prognostic factors for long-term survivors of breast cancer. Breast Cancer Res Treat 2008;107(3):309-30.

[14] Borresen-Dale AL. TP53 and breast cancer. Hum Mutat 2003;21(3):292-300.

[15] Lacroix M, Toillon RA, Leclercq G. p53 and breast cancer, an update. Endocr Relat Cancer 2006;13(2):293-325.

[16] Park D, Karesen R, Noren T, et al. Ki-67 expression in primary breast carcinomas and their axillary lymph node metastases: clinical implications. Virchows Arch 2007;451(1):11-8.

[17] de Azambuja E, Cardoso F, de Castro G, et al. Ki-67 as prognostic marker in early breast cancer: a metaanalysis of published studies involving 12,155 patients. Br J Cancer 2007;96(10):1504-13.

[18] Eden P, Ritz C, Rose C, et al. "Good Old" clinical markers have similar power in breast cancer prognosis as microarray gene expression profilers. Eur J Cancer 2004;40(12):1837-41.

[19] Riley RD, Abrams KR, Sutton AJ, et al. Reporting of prognostic markers: current problems and development of guidelines for evidence-based practice in the future. Br J Cancer 2003;88(8):1191-8.

[20] Verma S, Bal A, Joshi K, et al. Immunohistochemical characterization of molecular subtypes of invasive breast cancer: a study from North India. APMIS 2012;120(12):1008-19.

[21] Duffy MJ, Harbeck N, Nap M, et al. Clinical use of biomarkers in breast cancer: updated guidelines from the European Group on Tumor Markers (EGTM). European Journal of Cancer 2017;75:284-98.

[22] Fernandes RC, Bevilacqua JL, Soares IC, et al. Coordinated expression of ER, PR and HER-2 define different prognostic subtypes among poorly differentiated breast carcinomas. Histopathology 2009;55(3):346-52.

[23] Sorlie T. Molecular portraits of breast cancer: tumour subtypes as distinct disease entities. Eur J Cancer 2004;40(18):2667-75. 